\title{
Risk factors of brain metastases as initial failure in completely resected stage IIIA(N2) non-small cell lung cancer
}

\author{
Qin Zhang ${ }^{1,2}$, Xu-Wei Cai ${ }^{1,2}$, Wen Feng ${ }^{1,2}$, Wen Yu ${ }^{1,2}$, Xiao-Long Fu ${ }^{1,2}$ \\ ${ }^{1}$ Department of Radiation Oncology, Shanghai Chest Hospital, Shanghai Jiao Tong University, Shanghai 200030, China; ${ }^{2}$ Department of Radiation \\ Oncology, Fudan University Shanghai Cancer Center, Shanghai 200032, China \\ Contributions: (I) Conception and design: XL Fu; (II) Administrative support: Q Zhang; (III) Provision of study materials or patients: All authors; \\ (IV) Collection and assembly of data: All authors; (V) Data analysis and interpretation: All authors; (VI) Manuscript writing: All authors; (VII) Final \\ approval of manuscript: All authors. \\ Correspondence to: Xiao-Long Fu. Department of Radiation Oncology, Shanghai Chest Hospital, Shanghai Jiao Tong University, 241 West Huaihai \\ Road, Shanghai 200030, China. Email: xlfu1964@hotmail.com.
}

Background: This study aimed to identify the risk factors of brain metastases (BM) as the initial site of failure in patients with completely resected stage IIIA (N2) non-small-cell lung cancer (NSCLC).

Methods: From January 2005 and June 2012, the clinical data of 357 patients with completely resected stage IIIA (N2) NSCLC were reviewed in this study. Kaplan-Meier analysis was used to identify the incidence of $\mathrm{BM}$ as the initial site of failure and survival. To assess the risk factors of $\mathrm{BM}$, the log-rank test and Cox regression were used for univariate analysis and multivariate analysis, separately.

Result: Seventy-three (20.4\%) patients developed BM; 60 patients had BM as their initial site of failure. The 1-, 3-, and 5-year risk for patients developing BM as the initial site of failure was 9.1\%, 27.4\% and $35.4 \%$, respectively. Univariate analysis showed adenocarcinoma histology $(\mathrm{P}=0.000)$, number of regional $\mathrm{LN}>4(\mathrm{P}=0.018)$, multiple $\mathrm{N} 2$ stations $(\mathrm{P}=0.027)$, multiple region of $\mathrm{LN}$ involvement $(\mathrm{P}=0.010)$ were significantly associated with an increased risk of developing $\mathrm{BM}$ as the initial site of failure. Multivariate analysis showed adenocarcinoma $(\mathrm{P}=0.001$; HR $=0.150 ; 95 \% \mathrm{CI}, 0.047-0.479)$, multiple regions of $\mathrm{LN}$ involvement $(\mathrm{P}=0.015$; HR $=2.010$; 95\% CI, 1.146-3.524) were significantly associated with the high risk of developing $\mathrm{BM}$ as the initial site of failure. In patients with adenocarcinoma and multiple regions of LN involvement, the 5-year actuarial risk of BM as the initial failure was $47.6 \%$, respectively.

Conclusions: Adenocarcinoma and multiple regions of LN involvement were independent risk factors for $\mathrm{BM}$ as the initial failure in completely resected stage IIIA (N2) NSCLC. Prospective clinical trials are needed to verify the effect of PCI in the highest-risk subset we identified.

Keywords: Brain metastases (BM); non-small cell lung cancer (NSCLC); risk factor; adenocarcinoma and multiple region of $\mathrm{LN}$ involvement

Submitted Nov 11, 2019. Accepted for publication Jan 14, 2020.

doi: $10.21037 /$ atm.2020.02.72

View this article at: http://dx.doi.org/10.21037/atm.2020.02.72

\section{Introduction}

Approximately $30 \%$ of non-small-cell lung cancer (NSCLC) patients are initially diagnosed with locally advanced NSCLC (LA-NSCLC) diseases (1). About $20-50 \%$ of patients with NSCLC will develop brain metastases (BM) during their disease course (2-15). BM generally leads to poor prognosis and poor quality of life. In BM patients treated by surgery, stereotactic radiosurgery (SRS), whole brain radiotherapy (WBRT), and systemic therapy either individually or in combination, the median overall survival (OS) was less than 1 year (16-20). The frequency of BM in LA-NSCLC is much higher than that in early stage of NSCLC (4-7,11-13,21). The 5-year risk of developing BM 
was $10 \%$ in early stage NSCLC (6), while in the LA-NSCLC and stage IV NSCLC the risk is $30-50 \%(4-7,11-13,21)$. Therefore, early BM detection is crucial, which is helpful to select prevention strategies such as prophylactic cranial irradiation (PCI) to improve patient survival and quality of life.

Completely resected NSCLC patients with pathologically confirmed N2 disease are considered to be a heterogeneous population $(22,23)$, with 5 -year survival rates ranging from $10 \%$ to $30 \%$ (24). We aimed at this homogeneous patients with completely resected staged IIIA (N2) of LA-NSCLC, because the frequency of BM in early stage of NSCLC is relatively low, and the rate of locoregional and extracranial recurrence in stage IIIA is lower than that in stage IIIB and stage IV, should not obscure the positive impact of prevention strategies such as PCI on survival.

Radical resection of IIIA (N2) of LA-NSCLC not only can provide accurate pathological stage, but also have more detailed information on lymph node (LN) status. $\mathrm{LN}$ status is a major determinant of outcome in patients with NSCLC, but whether or not the LN status is a major determinant of $\mathrm{BM}$ is unclear. Different studies have conflicting result and the information about the extent of $\mathrm{LN}$ metastases is not very detailed $(4,6,7,11)$. In this study, we focused on completely resected staged IIIA (N2) of LA-NSCLC to explore the correlation between LN status and $\mathrm{BM}$, and identify the risk factor of $\mathrm{BM}$ as the initial site of failure and the potential highest risk candidates who may benefit from PCI.

\section{Method}

\section{Patients}

A retrospective review of patients with surgically staged IIIA NSCLC was conducted. This study was approved by the review board in the hospital. Between January 2005 and June 2012, 357 consecutive patients with pathological IIIA (N2) (pIIIA-N2) who underwent complete resection were identified. The eligibility criteria for the patient records were as follows: (I) lobectomy or ipsilateral pneumonectomy (based on the location of the primary cancer); (II) systematic mediastinal LN dissection or sampling at least three N2 stations (which must include subcarinal LN station); (III) margin-negative resection of all gross disease at microscopic analysis (surgical resection with microscopically tumourfree resection margins including the bronchial, venous and arterial stumps, peribronchial soft tissue, any peripheral margin near the tumor or additionally resected tissue); (IV) negative results of brain magnetic resonance imaging (MRI) as part of their initial staging; (V) histologically confirmed pIIIA-N2 NSCLC (stage pT1-3N2M0) according to the Union for International Cancer Control (UICC) 7th edition of TNM classification (25). Patients were excluded if they had synchronous or sequential second primary tumors.

Patients who received adjuvant chemotherapy or postoperative radiotherapy (PORT) were included in the study. Patients were excluded if they received neoadjuvant therapy (chemotherapy and/or radiotherapy). Adjuvant chemotherapy was routinely administered for the patients. Chemotherapy with platinum-based doublet anticancer drugs was recommended as a standard, but observation or alternative anticancer drugs were selected when patients refused to receive standard chemotherapy or had underlying diseases such asthenia under the advice of physicians. PORT was administered on the judgment of radiation oncologist and referring surgeon. 3D conformal radiation therapy (3D-CRT) technique was employed in all patients who had PORT. The planning target volume (PTV) was determined as the clinical target volume plus $0.5-0.8 \mathrm{~cm}$ margins. Radiation for all patients was delivered with $6 \mathrm{MV} \mathrm{X}$-ray from linear accelerator at 1.8/fraction, 5 days/week, to a total dose of 50.4 Gy. Doses were prescribed to the PTV.

\section{Follow-up of patients}

Generally, the patients were followed up every 3 months after surgery for 2 years, and every 6 months thereafter. During follow-up, regular evaluations included medical history, physical examination, complete blood count, thoracic CT, and abdominal ultrasound or CT. Other tests, such as PET-CT, were performed as clinically indicated. Brain MRI was not performed during the follow-up period. Contrast-enhanced brain MRI was performed if patients had suspicious symptoms or disease progress. Disease progression was determined by the physician based on available information, including clinical assessments, radiologic examination, and/or pathology reports.

\section{Variables}

The demographic and clinic pathologic variables of patients at the time of diagnosis were age, gender, smoking history, histology, histologic grade, tumor stage (T1, T2, T3), IIIA stage (IIIA1-2, IIIA3), laterality, type of surgery, vessel invasion, interstitial fibrosis, extra-capsular extension (ECE), clinical N2 ( $\mathrm{cN} 2$ ) factor, the number of regional LNs, 
involved N2 stations, distribution of metastatic nodes (skip N2 or non-skip N2), LN ratio (LNR), mediastinal lymph node (MLN) region involved, the presence of $\mathrm{LN}$ station 7, the presence of the highest MLN. Treatment-related variables were type of surgery, adjuvant chemotherapy, PORT. The cN2 lesions was defined as the MLN enlargement $\geq 1 \mathrm{~cm}$ in short axis on CT or positive uptake on PET-CT before surgery; The highest MLN was defined as one of the resected MLNs located closest to the head; LNR was defined as ratio of metastatic to examined nodes or LN ratio; skip N2 metastasis was defined as the MLN metastasis without N1 nodal metastasis; Region of LN involvement was divided into superior mediastinal area, sortic area and inferior mediastinal area according to Wang et al.'s study (7); Nonsmokers were defined as patients who had smoked $<100$ cigarettes in their lifetime. In contrast, smokers were categorized as patients who had smoked more than 100 cigarettes in their lifetime.

\section{Data analysis}

Progression-free survival (PFS) was defined as the time from surgery to the time of progression, death of any cause, or final follow-up. OS was defined as the time from surgery to death of any cause or final follow-up, with death defined as an event. Disease recurrence at the surgical margin, hilum, mediastinum, and supraclavicular LN regions was considered a local-regional failure. All other sites of failure, outside the local region were considered distant metastasis. Time to BM as their initial site of failure was measured from the date of surgery to the date of BM between the patients who developed distant metastases or both local and distant recurrence as the initial failure, with BM defined as an event. The cumulative incidence of BM and survival were determined using the Kaplan-Meier method. To assess risk factors for BM as their initial site of failure, log-rank test was used for univariate analysis, and cox regression was used for multivariate analysis. All data analyses were conducted with SPSS 18.0 software package. Statistically significant value was $\mathrm{P}<0.05$ (only keeping three digits after the decimal point).

\section{Results}

\section{Patient characteristics}

A total of 357 patients were included in this study from January 2005 to June 2012. The patients' baseline characteristic was summarized in Table 1. There were 219 men and 138 women with a median age 59 years old (range, 34-86 years). Of 357 identified patients, 216 (60.5\%) were adenocarcinoma, 177 (49.6\%) were smokers, 323 (90.5\%) received lobectomy, 315 (88.2\%) received adjuvant chemotherapy, and $70(19.6 \%)$ received PORT.

\section{Survival and failure}

The median follow-up time for 130 surviving patients was 40.4 months (range, 4.4-132 months). The median PFS was 19.9 months. The 1-, 3-, and 5-year PFS was 69.6\%, 29.8\% and $17.3 \%$, respectively (Figure $1 A$ ). The median OS was 43.5 months. The 1-, 3-, and 5-year OS was 91.6\%, 55.3\% and $35.9 \%$, respectively (Figure $1 B$ ). Disease progression was identified in $248(69.5 \%)$ patients. 90 experienced local recurrence; 215 developed distant metastases; 192 developed distant metastases (34 had both local and distant failure) as the first site of failure. Time to local recurrence and distant metastasis was showed in Figure 2. Of 192 patients who developed distant metastases or both local and distant recurrence as the initial failure, brain was the most common site. Figure 3 showed the cumulative risk of distant metastases in different sites. The median time from surgery to the diagnosis of $\mathrm{BM}$ as the initial site of failure was 13.5 months, and the time to develop extracranial recurrence as the initial site of failure was 14.3 months. Of the 357 patients, 73 (20.4\%) patients developed BM: 60 patients had BM as their initial site of failure; 13 patients developing BM at some point during their follow-up. The OS of patients with BM was significant poor than in patients without BM, and the median OS and 5 -year OS rates were 36.5 months, $16.7 \%$ and 45.6 months, $44.9 \%$, respectively $(\mathrm{P}=0.021)$ (Figure $4 A$ ). The similar was observed between patients with $\mathrm{BM}$ as the initial site of failure and without $\mathrm{BM}$ as the initial site of failure, the median OS and 5-year OS rates were 31.6 months, $10.1 \%$ and 46.6 months, $42.3 \%$, respectively $(\mathrm{P}=0.004)$ (Figure $4 B)$.

\section{Risk factors BM}

The 1-, 3-, and 5-year risk for patients developing BM as the initial site of failure was $9.1 \%, 27.4 \%$ and $35.4 \%$, respectively (Figure 5). Table 1 showed the rate of BM as the initial failure for different clinical and pathological factors and find several risk factors were more likely to develop $\mathrm{BM}$ as the initial failure. Univariate analysis showed adenocarcinoma histology $(\mathrm{P}=0.000)$, number of 
Table 1 Characteristics of patients

\begin{tabular}{|c|c|c|}
\hline Characteristic & No. of Patients $(\mathrm{N}=357)$ & $\%$ \\
\hline \multicolumn{3}{|l|}{ Age } \\
\hline$\leq 60$ & 208 & 58.3 \\
\hline$>60$ & 149 & 41.7 \\
\hline \multicolumn{3}{|l|}{ Gender } \\
\hline Male & 219 & 61.3 \\
\hline Female & 138 & 38.7 \\
\hline \multicolumn{3}{|l|}{ Smoking history } \\
\hline Never/light smoker & 180 & 50.4 \\
\hline Current/heavy smoker & 177 & 49.6 \\
\hline \multicolumn{3}{|l|}{ Histology } \\
\hline Adenocarcinoma & 216 & 60.5 \\
\hline No- Adenocarcinoma & 141 & 39.5 \\
\hline \multicolumn{3}{|l|}{ Tumor differentiation } \\
\hline Well/moderate & 184 & 51.5 \\
\hline Poor & 173 & 48.5 \\
\hline \multicolumn{3}{|l|}{ Pathologic T stage } \\
\hline $\mathrm{T} 1$ & 80 & 22.4 \\
\hline $\mathrm{T} 2$ & 239 & 66.9 \\
\hline T3 & 38 & 10.6 \\
\hline \multicolumn{3}{|l|}{ IIIA stage } \\
\hline IIIA1-2 & 193 & 54.1 \\
\hline IIIA-3 & 164 & 45.9 \\
\hline \multicolumn{3}{|l|}{ Tumor location } \\
\hline Left & 163 & 45.7 \\
\hline Right & 194 & 54.3 \\
\hline \multicolumn{3}{|l|}{ Type of surgery } \\
\hline Lobectomy & 323 & 90.5 \\
\hline Pneumonectomy & 34 & 9.5 \\
\hline \multicolumn{3}{|l|}{ Clinical $\mathrm{N}$ factor } \\
\hline N0,1 & 193 & 54.1 \\
\hline N2 & 164 & 45.9 \\
\hline \multicolumn{3}{|l|}{ Number of metastatic LNs } \\
\hline$\leq 4$ & 192 & 53.8 \\
\hline$>4$ & 165 & 46.2 \\
\hline
\end{tabular}

Table 1 (continued)
Table 1 (continued)

\begin{tabular}{|c|c|c|}
\hline Characteristic & No. of Patients $(\mathrm{N}=357)$ & $\%$ \\
\hline \multicolumn{3}{|c|}{ Involved N2 station } \\
\hline Single & 177 & 49.6 \\
\hline Multiple & 180 & 50.4 \\
\hline \multicolumn{3}{|c|}{ Distribution of MLN } \\
\hline Skip N2 & 120 & 33.6 \\
\hline No-skip N2 & 237 & 66.4 \\
\hline \multicolumn{3}{|l|}{ LNR } \\
\hline$\leq 20 \%$ & 172 & 48.2 \\
\hline$>20 \%$ & 185 & 51.8 \\
\hline \multicolumn{3}{|c|}{ MLN region involved } \\
\hline Single & 254 & 71.1 \\
\hline Multiple & 103 & 28.9 \\
\hline \multicolumn{3}{|l|}{ LN station 7} \\
\hline Negative & 220 & 61.6 \\
\hline Positive & 137 & 38.4 \\
\hline \multicolumn{3}{|c|}{ Highest MLN status } \\
\hline Negative & 197 & 55.2 \\
\hline Positive & 160 & 44.8 \\
\hline \multicolumn{3}{|l|}{ POCT } \\
\hline No & 42 & 11.8 \\
\hline Yes & 315 & 88.2 \\
\hline \multicolumn{3}{|l|}{ PORT } \\
\hline No & 287 & 80.4 \\
\hline Yes & 70 & 19.6 \\
\hline
\end{tabular}

MLN, mediastinal lymph node, LNR, lymph node ratio (defined as the ratio of metastatic to examined lymph nodes); PORT, postoperative radiotherapy; POCT, postoperative chemotherapy.

regional $\mathrm{LN}>4(\mathrm{P}=0.018)$, multiple $\mathrm{N} 2$ stations $(\mathrm{P}=0.027)$, multiple region of $\mathrm{LN}$ involvement $(\mathrm{P}=0.010)$ were significantly associated with an increased risk of developing $\mathrm{BM}$ as the initial site of failure. In multivariate analysis, adenocarcinoma $(\mathrm{P}=0.001$; HR $=0.150$; 95\% CI, 0.0470.479), multiple regions of $\mathrm{LN}$ involvement $(\mathrm{P}=0.015$; HR $=2.010 ; 95 \%$ CI, 1.146-3.524) remained as the high risk of $\mathrm{BM}$ as the initial site of failure. Incidence of BM in relation to histology and LN status in completely resected staged IIIA (N2) NSCLC showed in Table 2. In patients with 

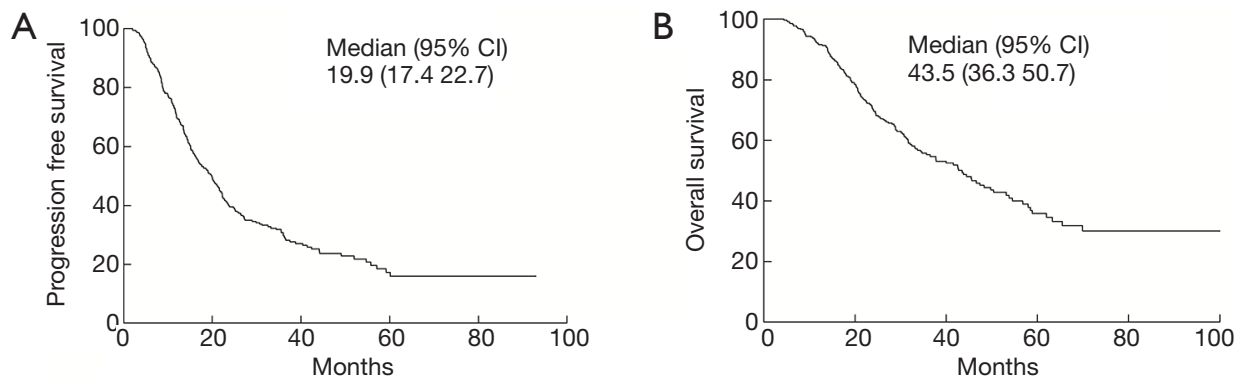

Figure 1 PFS and OS for all the patients. (A) PFS: the median PFS was 19.9 months. (B) OS: the median OS was 43.5 months.
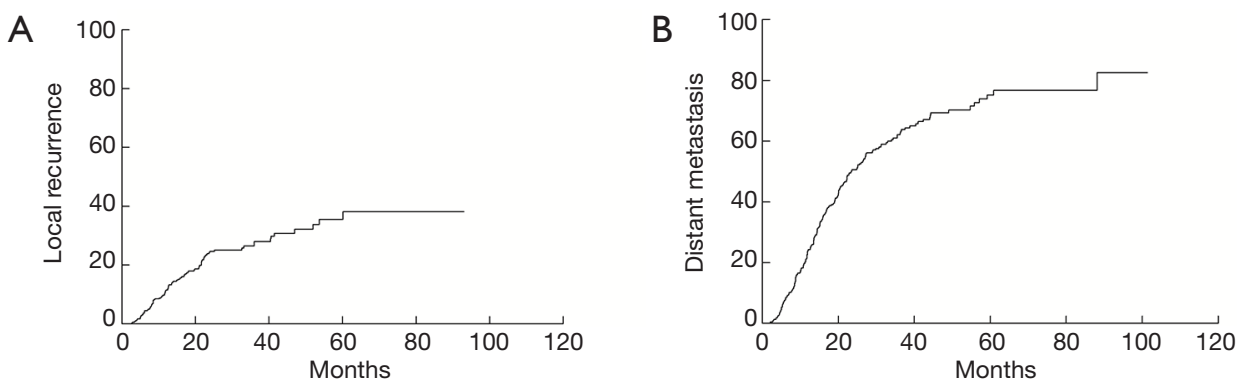

Figure 2 Time to Local recurrence and distant metastasis. (A) local recurrence; (B) distant metastasis.

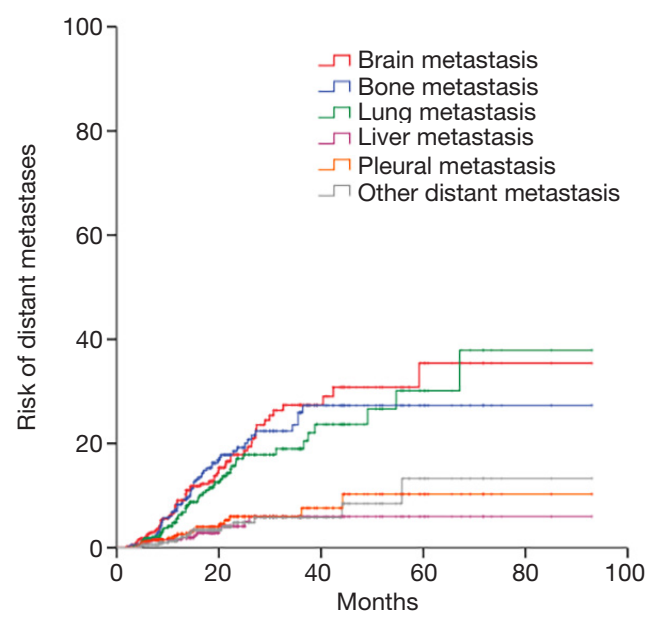

Figure 3 The cumulative risk of distant metastasis in different sites.

adenocarcinoma and multiple regions of $\mathrm{LN}$ involvement $(\mathrm{n}=84)$, the 1-, 3-, and 5-year actuarial risk of developing $\mathrm{BM}$ as the initial site of failure was $19.0 \%, 47.6 \%$, and $47.6 \%$, respectively. In patients with adenocarcinoma and single region of LN involvement $(\mathrm{n}=173)$, the $1-, 3-$, and 5 -year cumulative risk of $\mathrm{BM}$ as the initial site of failure was $8.9 \%, 28.5 \%$, and $40.6 \%$, respectively. In patients with non- adenocarcinoma and multiple region of $\mathrm{LN}$ involvement $(\mathrm{n}=19)$ or patients with non-adenocarcinoma and single region of LN involvement ( $\mathrm{n}=81)$, the 1-, 3-, and 5-year actuarial risk of developing BM was obviously lower than that in patients with adenocarcinoma and single region of $\mathrm{LN}$ involvement. The differences among the groups with both, one and none of the two risk factors were statistically significant $(\mathrm{P}=0.000)$ (Figure 6).

\section{Discussion}

Chemotherapy combined with radiotherapy and/or surgery significantly reduces extracranial distant metastases and improves survival among patients with LA-NSCLC; nevertheless, combined-modality therapy does not decrease the relatively high rate of $\mathrm{BM}$. The frequency of BM increases as the survival improved. Systemic chemotherapy does not decrease the relatively high rate of BM, because it is difficult to penetrate the blood-brain barrier and delivery drugs to the BM leaving the brain untreated (18,26-28). High risk of $\mathrm{BM}$ has become the critical factor influencing the prognosis of LA-NSCLC patients $(11,26,27,29)$. Because PCI has shown effectiveness in SCLC, some groups conducted large clinical trials to evaluate whether 

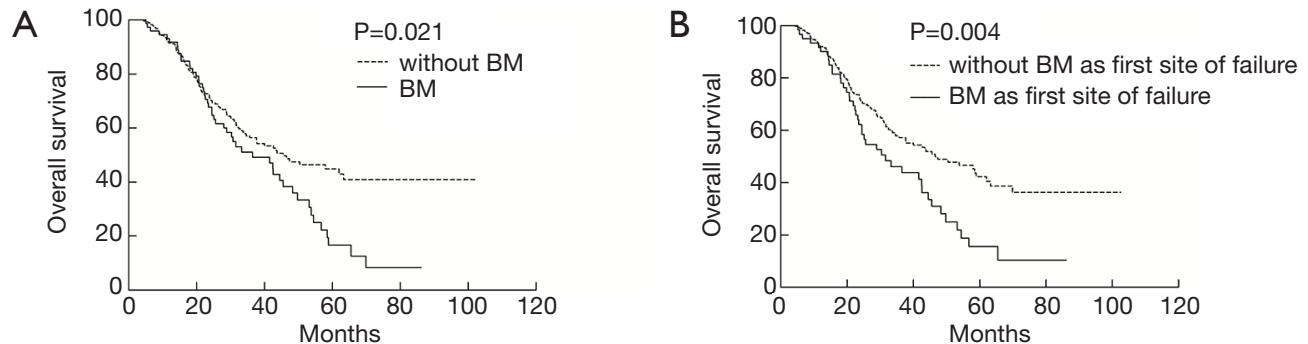

Figure 4 Kaplan-Meier survival curves. (A) the OS in patients with BM or without BM; (B) the OS in patients with BM or without BM as the initial site of failure. BM, brain metastases.

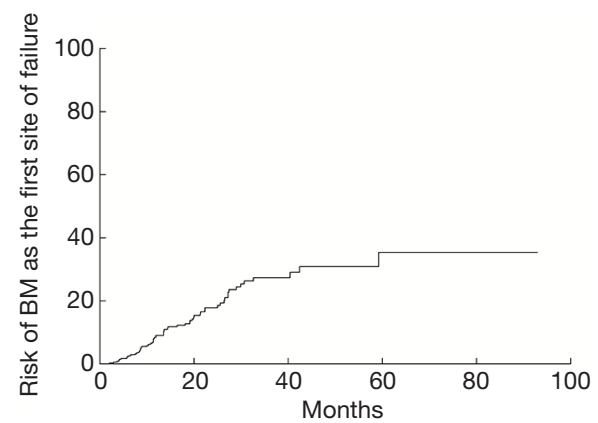

Figure 5 The risk for patients developing $\mathrm{BM}$ as the initial site of failure. BM, brain metastases.

LA-NSCLC patients can benefit from PC (30-34). To date, in NSCLC PCI has been proved to reduce the probability and/or delay the BM, but it fails to benefit the survival in several randomized studies $(31,35,36)]$. PCI also has side effects on mental capacities such as cognition disorders, memory deterioration. Radiation Therapy Oncology Group (RTOG) 0214 also suggests that PCI may not suitable for all patients and assessing PCI in NSCLC should choose high risk of $\mathrm{BM}$ patients with relative good locoregional and extracranial control, who are the most likely to derive survival benefit from PCI. Therefore, we focused on patients with completely resected pIIIA-N2 NSCLC, assessed risk factors for developing BM as the initial site of failure, and defined the highest-risk subgroup most likely to benefit from PCI.

Most previous studies aimed at the high risk factors of developing BM at some point during their clinical course, not at the high risk factors of developing $\mathrm{BM}$ as their first site of failure in NSCLC. The high-risk patients of BM as their first site of failure are not well defined. In our study, multivariate analysis showed that adenocarcinoma and multiple regions of $\mathrm{LN}$ involvement were associated with high incidence of $\mathrm{BM}$ as the first failure. An increased risk in patients with adenocarcinoma or non-squamous cell cancer was also noted by many studies on NSCLC (3-5,7-11,37,38). Our study produced a similar result: adenocarcinoma was an independent risk factor of developing BM as the first failure. But whether or not the LN status (multiple regions of $\mathrm{LN}$ involvement) is a major determinant of $\mathrm{BM}$ is unclear. Many studies have found that the number and degree of MLN metastases correlated with prognosis of lung cancer, such as the number of resected LNs, the number of regional LNs, LNR, cN2 factor, HM, skip N2 all have been reported as independent prognosis factors in patients with NSCLC (39-49). In pIIIA-N2 NSCLC, the recurrence and the metastasis rate were also affected by the number and degree of MLN metastases (40,43,46,48-50). However, which LN status can predict a high risk of $\mathrm{BM}$ is not well defined. So far, different studies have conflicting result and the information about the extent of LN metastases is not very detailed. Ding et al. (4) observed that $\mathrm{LNR} \geq 30 \%$ associated with an increased risk of $\mathrm{BM}$ in completely resected pIIIA-N2. Hubbs et al. (6) reported that hilar LN involvement predicts a high risk of BM of patients treated surgically for early stage NSCLC. Wang et al. (7) found that multiple $\mathrm{LN}$ regions with metastases and the number of metastases $\mathrm{LN} \geq 4$ influenced the frequency of BM in resected III-N2 NSCLC. Mamon et al. (11) inferred that residual nodal involvement as an important factor in predicting BM in surgically staged IIIA NSCLC treated with combined therapy. Compared with the previous studies, our study included the largest heterogeneous population (357 patients) of complete resected stage IIIA (N2) NSCLC and had more detailed information on LN metastases status and other clinical characteristics. In our study, on univariate analysis, number of regional LNs $>4$, $\mathrm{N} 2$ station, multiple involved N2 stations and multiple regions of MLN involvement were associated with risk of 
Table 2 Risk of BM

\begin{tabular}{|c|c|c|c|c|c|c|c|}
\hline Factors & $\begin{array}{c}\text { Number of } \\
\text { patients }\end{array}$ & \multicolumn{4}{|c|}{ Univariate analysis (first BM incidence\%) } & \multicolumn{2}{|c|}{ Multivariate analysis } \\
\hline Age & & & & & 0.332 & & \\
\hline$\leq 60$ & 208 & 8.5 & 30.2 & 38.4 & & & \\
\hline$>60$ & 149 & 10.0 & 23.0 & 27.8 & & & \\
\hline Male & 219 & 9.1 & 23.1 & 34.5 & & & \\
\hline Female & 138 & 8.8 & $32 . .1$ & 35.9 & & & \\
\hline Smoking history & & & & & 0.181 & & \\
\hline No & 180 & 8.1 & 31.2 & 37.2 & & & \\
\hline Adenocarcinoma & 216 & 11.9 & 33.4 & 44.0 & & & \\
\hline Non-adenocarcinoma & 141 & 1.4 & 9.4 & 9.4 & & & \\
\hline Tumor differentiation & & & & & 0.720 & & \\
\hline Well/ Moderate & 184 & 8.6 & 29.5 & 37.3 & & & \\
\hline Poor & 173 & 9.6 & 25.3 & 32.3 & & & \\
\hline Pathologic T stage & & & & & 0.510 & & \\
\hline $\mathrm{T} 1$ & 80 & 12.3 & 38.1 & 53.6 & & & \\
\hline $\mathrm{T} 2$ & 239 & 8.5 & 24.3 & 29.4 & & & \\
\hline Left & 163 & 8.8 & 21.2 & 34.1 & & & \\
\hline Right & 194 & 9.3 & 32.6 & 35.9 & & & \\
\hline Type of surgery & & & & & 0.798 & & \\
\hline Lobectomy & 323 & 8.5 & 27.3 & 35.6 & & & \\
\hline Pneumonectomy & 34 & 15.1 & 27.3 & 27.3 & & & \\
\hline Clinical $\mathrm{N}$ factor & & & & & 0.231 & & \\
\hline No,1 & 193 & 8.3 & 25.1 & 34.1 & & & \\
\hline N2 & 164 & 10 & 30.6 & 36.4 & & & \\
\hline $\mathrm{N}$ of metastatic LNs & & & & & 0.018 & & \\
\hline$\leq 4$ & 192 & 5.3 & 24.1 & 26.3 & & & \\
\hline$>4$ & 165 & 13.8 & 31.8 & 69.7 & & & \\
\hline
\end{tabular}

Table 2 (continued) 
Table 2 (continued)

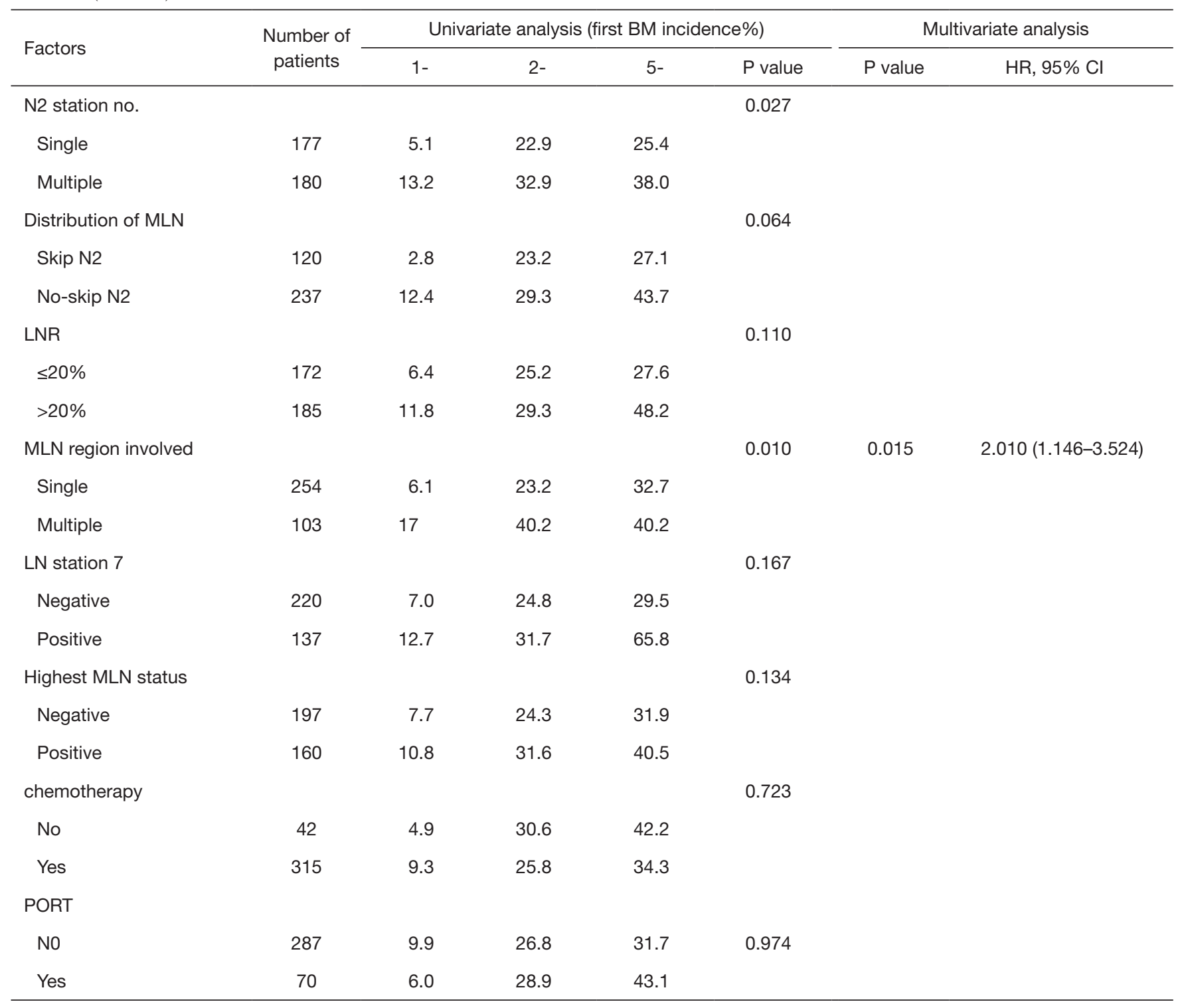

developing BM. On multivariate analysis, only multiple regions of MLN involvement associated with high incidence of BM as the first failure. To our knowledge, our study is the largest retrospective study having the most detailed information on $\mathrm{LN}$ metastases from a single institution in studying the risk factors of $\mathrm{BM}$ as the initial failure in completely resected pIIIA-N2 patients.

In recent years, many researchers have reported risk factors of developing BM. Adenocarcinoma or nonsquamous cell carcinoma is more likely to developing BM. However, it was not consistent with all studies. Some studies did not find a correlation between histology and developing BM $(6,13-15,33)$. There are also other previous studies find different factors correlated with BM in NSCLC; the factors include age $(3,14,37,51,52)$, gender (3), serum levels of tumor markers (carcinoembryonic antigen, neuronspecific enolase, CA125) (8,37), the epidermal growth factor receptor (EGFR) mutation status (2), adjuvant or neoadjuvant therapy $(5,7,15)$, extent of disease $(7,15,38)$, incomplete resection (7).Tumor status is an independent prognosis factors in patients with NSCLC. Tumor size is associated with the risk of BM in NSCLC $(6,52)$. Hubbs 


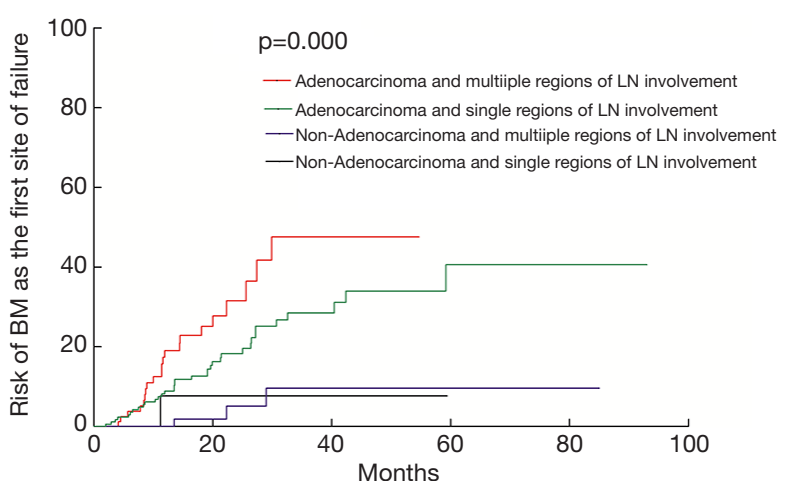

Figure 6 The differences among the groups with both, one and none of the two risk factors.

et al. (6) analyzed of 975 patients with early stage NSCLC, in whom larger tumor size were risk of BM. Mujoomdar et al. (9) demonstrated that in a cohort of 264 stage I-IV patients, the probability of BM is correlated with size of the primary tumor. Bajard et al. (51) observed that T4 tumor status is a factor factors predictive of BMs in a group of stages I-III NSCLC patients. However, we did not find such a relationship. There are also other investigators who also did not find a relationship between tumor size and BM $(4,5,37)$. Systemic therapy is associated with an increased risk of BM in several previous studies. It is reported that adjuvant chemotherapy or neoadjuvant chemotherapy is a statistically significant factor of BM $(7,10)$. However, many other studies did not find that chemotherapy and TKIs were significantly related with the risk of BM $(4,37)$. In our study, no significant correlation between the system therapy schedule and BM was found. We also did not find age, sex, or primary tumor location etc. correlate with BM. Most of those previous studies often include heterogeneous populations and the results are inconsistent. Our study described 357 patients with stage IIIA (N2) NSCLC treated with complete resection of the primary lesion and LN dissection. All patients in this study were surgically staged. In our study, only adenocarcinoma histology and multiple region of $\mathrm{LN}$ involvement were associated with high incidence of $\mathrm{BM}$ as the first failure. It also suggests the importance of brain MRI during the follow-up to detect the $\mathrm{BM}$ in high-risk patients of brain.

In RTOG 0214, PCI has not been shown to improve OS significantly, one possible explanation is that the high rates of locoregional and extracranial distant relapse overwhelmed any survival benefits from PCI in LA-NSCLC; another possible explanation is that it had a relative low BM risk, only
$18 \%$ of patients in the observation, it is much lower than that of SCLC, in which PCI has been proved to bring survival benefit. We focused on $\mathrm{BM}$ as the initial site of failure in completely resected PIIIA-N2 NSCLC, because the rate of BM significantly higher than early stage of NSCLC, and the locoregional recurrence and extracranial failure is relatively lower than stage IIIB and stage IV NSCLC. Assessment of PCI on this group of patients may not override the positive impact of PCI on survival. In our study, in patients with adenocarcinoma and multiple regions of $\mathrm{LN}$ involvement $(\mathrm{n}=84)$, the 1-, 3-, and 5-year actuarial risk of developing BM as the initial site of failure was $19.0 \%, 47.6 \%$, and $47.6 \%$, respectively. The subgroup of patients had sufficient BM rates to identify the high-risk patients who are the most likely to derive a survival benefit from PCI. It is helpful to conduct a future randomized, controlled trial to investigate PCI in the highest-risk group of patients we identified.

Our study also had several limitations. First, this is a retrospective study. The study may have selection bias and the results should be interpreted cautiously. Second, although we targeted a homogeneous largest population with completely resected pIIIA-N2, there was also some heterogeneity in treatment parameters. This heterogeneity was mainly caused by the variability in PORT and adjuvant chemotherapy regimens. Not every patients received PETCT and/or mediastinoscopy, cannot completely excluded the mediastinal staging considering $\mathrm{N} 3$ disease, and criteria for upfront surgery in stage IIIA(N2) tumors mainly depends on clinical staging, and excluding patients who received neoadjuvant therapy the authors are likely excluding patients with poorer risk factors. Third, EGFR mutation status was not known in this study. Two studies have conflicting results about whether or not the EGFR mutations is an independent risk factor of BM. Shin et al. (2) found EGFR status had no influence upon the incidence of BM at the diagnosis and after the resection in 3 wwwww 14 patients of pulmonary adenocarcinoma. Stanic et al. (53) demonstrated that non-significant association between EGFR mutation status and $\mathrm{BM}$ at the time of diagnosis and no influence upon the cumulative incidence of BM. These two studies include heterogeneous populations with respect to pre/postoperative stage. We are planning to examine EGFR mutation status of patients with staged IIIA (N2) adenocarcinoma to investigate the correlation of EGFR mutations and BM.

\section{Conclusions}

This study demonstrated that adenocarcinoma and 
multiple regions of $\mathrm{LN}$ involvement were independent risk factors for $\mathrm{BM}$ as the initial failure in completely resected pIIIA-N2 NSCLC. Patients with adenocarcinoma and multiple regions of $\mathrm{LN}$ involvement are at the highest risk of developing BM as the initial failure, and may receive a greater benefit from PCI. Prospective clinical trials are needed to verify the effect of PCI in the highest-risk subgroup we identified.

\section{Acknowledgments}

Funding: This work was supported by National Key Research R\&D Program of China [2016YFC0905502]; the project of multi-center clinical research, Shanghai Jiao Tong University School of Medicine [DLY201619]; and Shanghai Chest Hospital Project of Collaborative Innovation [YJXT20190101].

\section{Footnote}

Conflicts of Interest: The authors have no conflicts of interest to declare.

Ethical Statement: The authors are accountable for all aspects of the work in ensuring that questions related to the accuracy or integrity of any part of the work are appropriately investigated and resolved. The study was approved by the Ethics Committee of Shanghai Chest Hospital. Written informed consent was obtained from all patients.

Open Access Statement: This is an Open Access article distributed in accordance with the Creative Commons Attribution-NonCommercial-NoDerivs 4.0 International License (CC BY-NC-ND 4.0), which permits the noncommercial replication and distribution of the article with the strict proviso that no changes or edits are made and the original work is properly cited (including links to both the formal publication through the relevant DOI and the license). See: https://creativecommons.org/licenses/by-nc-nd/4.0/.

\section{References}

1. Morgensztern D, Ng SH, Gao F, et al. Trends in stage distribution for patients with non-small cell lung cancer: a National Cancer Database survey. J Thorac Oncol 2010;5:29-33.

2. Shin DY, Na II, Kim CH, et al. EGFR mutation and brain metastasis in pulmonary adenocarcinomas. J Thorac Oncol 2014;9:195-9.

3. Hsiao, SH, Chung, CL, Chou, YT, et al. Identification of subgroup patients with stage IIIB/IV non-small cell lung cancer at higher risk for brain metastases. Lung Cancer 2013;82:319-23.

4. Ding X, Dai H, Hui Z, et al. Risk factors of brain metastases in completely resected pathological stage IIIA-N2 non-small cell lung cancer. Radiat Oncol 2012;7:119.

5. Petrović $\mathrm{M}$, Ilic N, Loncarevic $\mathrm{O}$, et al. Risk factors for brain metastases in surgically staged IIIA non-small cell lung cancer patients treated with surgery, radiotherapy and chemotherapy. Vojnosanit Pregl 2011;68:643-9.

6. Hubbs JL, Boyd JA, Hollis D, et al. Factors associated with the development of brain metastases: analysis of 975 patients with early stage nonsmall cell lung cancer. Cancer 2010;116:5038-46.

7. Wang SY, Ye X, Ou W, et al. Risk of cerebral metastases for postoperative locally advanced non-small-cell lung cancer. Lung Cancer 2009;64:238-43.

8. Arrieta O, Saavedra-Perez D, Kuri R, et al. Brain metastasis development and poor survival associated with carcinoembryonic antigen (CEA) level in advanced nonsmall cell lung cancer: a prospective analysis. BMC Cancer 2009;9:119.

9. Mujoomdar A, Austin JH, Malhotra R, et al. Clinical predictors of metastatic disease to the brain from nonsmall cell lung carcinoma: primary tumor size, cell type, and lymph node metastases. Radiology 2007;242:882-8.

10. Chen AM, Jahan TM, Jablons DM, et al. Risk of cerebral metastases and neurological death after pathological complete response to neoadjuvant therapy for locally advanced nonsmall-cell lung cancer: clinical implications for the subsequent management of the brain. Cancer 2007;109:1668-75.

11. Mamon HJ, Yeap BY, Janne PA, et al. High risk of brain metastases in surgically staged IIIA non-small-cell lung cancer patients treated with surgery, chemotherapy, and radiation. J Clin Oncol 2005;23:1530-7.

12. Gaspar LE, Chansky K, Albain KS, et al. Time from treatment to subsequent diagnosis of brain metastases in stage III non-small-cell lung cancer: a retrospective review by the Southwest Oncology Group. J Clin Oncol 2005;23:2955-61.

13. Carolan H, Sun AY, Bezjak A, et al. Does the incidence and outcome of brain metastases in locally advanced non-small cell lung cancer justify prophylactic cranial irradiation or 
early detection? Lung Cancer 2005;49:109-15.

14. Ceresoli GL, Reni M, Chiesa G, et al. Brain metastases in locally advanced nonsmall cell lung carcinoma after multimodality treatment: risk factors analysis. Cancer 2002;95:605-12.

15. Robnett TJ, Machtay M, Stevenson JP, et al. Factors affecting the risk of brain metastases after definitive chemoradiation for locally advanced non-small-cell lung carcinoma. J Clin Oncol 2001;19:1344-9.

16. Barlesi F, Gervais R, Lena H, et al. Pemetrexed and cisplatin as first-line chemotherapy for advanced nonsmall-cell lung cancer (NSCLC) with asymptomatic inoperable brain metastases: a multicenter phase II trial (GFPC 07-01). Ann Oncol 2011;22:2466-70.

17. Andrews DW, Scott CB, Sperduto PW, et al. Whole brain radiation therapy with or without stereotactic radiosurgery boost for patients with one to three brain metastases: phase III results of the RTOG 9508 randomised trial. Lancet 2004;363:1665-72.

18. Cortes J, Rodriguez J, Aramendia JM, et al. Frontline paclitaxel/cisplatin-based chemotherapy in brain metastases from non-small-cell lung cancer. Oncology 2003;64:28-35.

19. Vecht CJ, Haaxma-Reiche H, Noordijk EM, et al. Treatment of single brain metastasis: radiotherapy alone or combined with neurosurgery? Ann Neurol 1993;33:583-90.

20. Patchell RA, Tibbs PA, Walsh JW, et al. A randomized trial of surgery in the treatment of single metastases to the brain. N Engl J Med 1990;322:494-500.

21. Zhang B, Wang S, Qu W, et al. Clinical verification of a mathematical model for prediction of brain metastases in patients with locally advanced non-small cell lung cancer. Zhongguo Fei Ai Za Zhi 2008;11:414-9.

22. Andre F, Grunenwald D, Pignon JP, et al. Survival of patients with resected N2 non-small-cell lung cancer: evidence for a subclassification and implications. J Clin Oncol 2000;18:2981-9.

23. Inoue $M$, Sawabata N, Takeda $S$, et al. Results of surgical intervention for p-stage IIIA (N2) non-small cell lung cancer: acceptable prognosis predicted by complete resection in patients with single N2 disease with primary tumor in the upper lobe. J Thorac Cardiovasc Surg 2004;127:1100-6.

24. Spira A, Ettinger DS. Multidisciplinary management of lung cancer. N Engl J Med 2004;350:379-92.

25. Detterbeck FC, Boffa DJ, Tanoue LT. The new lung cancer staging system. Chest 2009;136:260-71.
26. Andre F, Grunenwald D, Pujol JL, et al. Patterns of relapse of N2 non-small-cell lung carcinoma patients treated with preoperative chemotherapy: should prophylactic cranial irradiation be reconsidered? Cancer 2001;91:2394-400.

27. Cox JD, Scott CB, Byhardt RW, et al. Addition of chemotherapy to radiation therapy alters failure patterns by cell type within non-small cell carcinoma of lung (NSCCL): analysis of radiation therapy oncology group (RTOG) trials. Int J Radiat Oncol Biol Phys 1999;43:505-9.

28. Komaki R, Scott CB, Sause WT, et al. Induction cisplatin/ vinblastine and irradiation vs. irradiation in unresectable squamous cell lung cancer: failure patterns by cell type in RTOG 88-08/ECOG 4588. Radiation Therapy Oncology Group. Eastern Cooperative Oncology Group. Int J Radiat Oncol Biol Phys 1997;39:537-44.

29. Komaki R, Scott CB, Byhardt R, et al. Failure patterns by prognostic group determined by recursive partitioning analysis (RPA) of 1547 patients on four radiation therapy oncology group (RTOG) studies in inoperable nonsmallcell lung cancer (NSCLC). Int J Radiat Oncol Biol Phys 1998;42:263-7.

30. Gondi V, Paulus R, Bruner DW, et al. Decline in tested and self-reported cognitive functioning after prophylactic cranial irradiation for lung cancer: pooled secondary analysis of Radiation Therapy Oncology Group randomized trials 0212 and 0214. Int J Radiat Oncol Biol Phys 2013;86:656-64.

31. Gore EM, Bae K, Wong SJ, et al. Phase III comparison of prophylactic cranial irradiation versus observation in patients with locally advanced non-small-cell lung cancer: primary analysis of radiation therapy oncology group study RTOG 0214. J Clin Oncol 2011;29:272-8.

32. Sun A, Bae K, Gore EM, et al. Phase III trial of prophylactic cranial irradiation compared with observation in patients with locally advanced non-small-cell lung cancer: neurocognitive and quality-of-life analysis. J Clin Oncol 2011;29:279-86.

33. Pöttgen C, Eberhardt W, Grannass A, et al. Prophylactic cranial irradiation in operable stage IIIA non small-cell lung cancer treated with neoadjuvant chemoradiotherapy: results from a German multicenter randomized trial. J Clin Oncol 2007;25:4987-92.

34. Stuschke M, Eberhardt W, Pottgen C, et al. Prophylactic cranial irradiation in locally advanced non-small-cell lung cancer after multimodality treatment: long-term follow-up and investigations of late neuropsychologic effects. J Clin Oncol 1999;17:2700-9. 
35. Russell AH, Pajak TE, Selim HM, et al. Prophylactic cranial irradiation for lung cancer patients at high risk for development of cerebral metastasis: results of a prospective randomized trial conducted by the Radiation Therapy Oncology Group. Int J Radiat Oncol Biol Phys 1991;21:637-43.

36. Umsawasdi T, Valdivieso M, Chen TT, et al. Role of elective brain irradiation during combined chemoradiotherapy for limited disease non-small cell lung cancer. J Neurooncol 1984;2:253-9.

37. Ji Z, Bi N, Wang J, et al. Risk factors for brain metastases in locally advanced non-small cell lung cancer with definitive chest radiation. Int J Radiat Oncol Biol Phys 2014;89:330-7.

38. Na II, Lee TH, Choe DH, et al. A diagnostic model to detect silent brain metastases in patients with non-small cell lung cancer. Eur J Cancer 2008;44:2411-7.

39. Qiu C, Dong W, Su B, et al. The prognostic value of ratiobased lymph node staging in resected non-small-cell lung cancer. J Thorac Oncol 2013;8:429-35.

40. Yan D, Wei P, An G, et al. Prognostic potential of ERCC1 protein expression and clinicopathologic factors in stage III/N2 non-small cell lung cancer. J Cardiothorac Surg 2013;8:149.

41. Matsuguma H, Oki I, Nakahara R, et al. Proposal of new nodal classifications for non-small-cell lung cancer based on the number and ratio of metastatic lymph nodes. Eur J Cardiothorac Surg 2012;41:19-24.

42. Nwogu CE, Groman A, Fahey D, et al. Number of lymph nodes and metastatic lymph node ratio are associated with survival in lung cancer. Ann Thorac Surg 2012;93:1614-9; discussion 1619-20.

43. Nakagiri T, Sawabata N, Funaki S, et al. Validation of $\mathrm{pN} 2$ sub-classifications in patients with pathological stage IIIA $\mathrm{N} 2$ non-small cell lung cancer. Interact Cardiovasc Thorac Surg 2011;12:733-8.

44. Jonnalagadda S, Arcinega J, Smith C, et al. Validation of the lymph node ratio as a prognostic factor in patients with
N1 nonsmall cell lung cancer. Cancer 2011;117:4724-31.

45. Saji, H, Tsuboi, M, Yoshida, K, et al. Prognostic impact of number of resected and involved lymph nodes at complete resection on survival in non-small cell lung cancer. J Thorac Oncol 2011;6:1865-71.

46. Hanagiri T, Takenaka M, Oka S, et al. Clinical significance in the number of involved lymph nodes in patients that underwent surgery for pathological stage III-N2 non-small cell lung cancer. J Cardiothorac Surg 2011;6:144.

47. Wei S, Asamura H, Kawachi R, et al. Which is the better prognostic factor for resected non-small cell lung cancer: the number of metastatic lymph nodes or the currently used nodal stage classification? J Thorac Oncol 2011;6:310-8.

48. Decaluwé H, De Leyn P, Vansteenkiste J, et al. Surgical multimodality treatment for baseline resectable stage IIIA-N2 non-small cell lung cancer. Degree of mediastinal lymph node involvement and impact on survival. Eur J Cardiothorac Surg 2009;36:433-9.

49. Sakao Y, Miyamoto H, Yamazaki A, et al. Prognostic significance of metastasis to the highest mediastinal lymph node in nonsmall cell lung cancer. Ann Thorac Surg 2006;81:292-7.

50. Kim DW, Yun JS, Song SY, et al. The Prognosis According to Patterns of Mediastinal Lymph Node Metastasis in Pathologic Stage IIIA/N2 Non-Small Cell Lung Cancer. Korean J Thorac Cardiovasc Surg 2014;47:13-9.

51. Bajard A, Westeel V, Dubiez A, et al. Multivariate analysis of factors predictive of brain metastases in localised nonsmall cell lung carcinoma. Lung Cancer 2004;45:317-23.

52. Dimitropoulos C, Hillas G, Nikolakopoulou S, et al. Prophylactic cranial irradiation in non-small cell lung cancer patients: who might be the candidates? Cancer Manag Res 2011;3:287-94.

53. Stanic K, Zwitter M, Hitij NT, et al. Brain metastases in lung adenocarcinoma: impact of EGFR mutation status on incidence and survival. Radiol Oncol 2014;48:173-83.
Cite this article as: Zhang Q, Cai XW, Feng W, Yu W, Fu XL. Risk factors of brain metastases as initial failure in completely resected stage IIIA(N2) non-small cell lung cancer. Ann Transl Med 2020;8(6):374. doi: 10.21037/atm.2020.02.72 